\title{
Sustainable and Smart: Rethinking What a Smart Home Is
}

\author{
Maha Salman \\ RCC Institute of Technology, \\ Yorkville University \\ Toronto, Canada \\ msalman@yorkvilleu.ca
}

\author{
Samar Sabie \\ Dept of Computer Science \\ University of Toronto \\ Toronto, Canada \\ ssabie@cs.toronto.edu
}

\author{
Steve Easterbrook \\ Dept of Computer Science \\ University of Toronto \\ Toronto, Canada \\ sme@cs.toronto.edu
}

\author{
Josie Abate \\ RCC Institute of Technology, \\ Yorkville University \\ Toronto, Canada \\ jabate @ rcc.yorkvilleu.ca
}

\begin{abstract}
The term Smart Home typically refers to dwellings augmented with high-tech responsive systems such that heating, air conditioning, lighting, appliances, entertainment outlets, and architectural components are computerized and managed, often via a remote control. Smart homes promise comfort, convenience, and resource conservation in the near future. Yet the notion of increased dependency on technology for comfort and efficiency (and hence, sustainably) needs to be revised. While we (justifiably) expect our dwellings to use technological advances to sense and respond to our needs, a growing body of literature [1-5] warns against increased dependencies and amplified complexification, given the resource depletion anticipated in the future. Through examples and discussions drawn primarily from vernacular architecture discourse, this paper addresses this dichotomy. We investigate how smart homes can be re-defined to better fit sustainability goals while anticipating technology limitations. We introduce members of the ICT4S community to the sustainability potentials of vernacular domestic architecture and inspire them by its smart responses to human needs and harsh conditions. And finally, we argue that re-employing tried-and-true vernacular techniques in conjunction with ICT systems can offer smart yet simple and feasible solutions to future housing needs while being inherently more sustainable from an environmental and operational stance.
\end{abstract}

Index Terms - Smart Home, Sustainability, Vernacular Architecture, ICT Systems

\section{INTRODUCTION}

As early as the 1920s, architects questioned the static nature of their living spaces and whether they could become more malleable and responsive to user needs. Ludwig Mies van der Rohe and Le Corbusier, two renowned architects and leaders of modern architecture, abandoned the conservative idealism of the conventional home and advocated novel orientations. These included celebrating the new machine age, ridding architecture from unnecessary frills such as ornamentation, and building in a standardized, manufactured style akin to factory assembly lines. Le Corbusier even famously declared " $[\mathrm{t}] \mathrm{he}$ house is a machine for living". While Mies and Corbusier's built works were more architectural and metaphoric than rationalist engineering feats, their visions of the mechanization of design contributed to a new ideal for the home of the $20^{\text {th }}$ century.

Besides the incorporation of mass production, contemporary buildings on the domestic scale have remained relatively orthodox despite the availability of technological advances to foster reformation and transformability. In fact, housing has not changed much since the early $20^{\text {th }}$ century in both typology and function. However, recent work in ubiquitous computing, the internet of things, and green architecture is striving to bring technological innovation to future homes, through the idea of the smart home [6].

But smart does not necessarily mean sustainable [7]. In this paper we contrast the techno-centric view of the smart home with the adoption of simpler, vernacular, architectural approaches to sustainable housing. The former tend to assume that technology can deliver a uniformity of comfort and convenience to homeowners around the world, irrespective of local conditions and needs. The latter are based on local knowledge and acknowledge local resources and constraints, to provide highly context-specific solutions that are inherently sustainable.

\section{THE MEANING OF A SMART \& SUSTAINABLE HOME}

Smart Home USA, a major distributor for housing technology systems, defines the smart home to their clients as a domicile which provides comfort, security, energy efficiency and convenience. It is “ $\ldots$ a residence that has appliances, lighting, heating, air conditioning, TVs, computers, entertainment audio $\&$ video systems, security, and camera systems that are capable of communicating with one another and can be controlled remotely by a time schedule, from any room in the home, as well as remotely from any location in the world by phone or internet..." [8]. This definition depicts the multitude of software and hardware technologies currently manufactured or under development to enhance living spaces, minimize resource consumption and emissions, and anticipate/support user needs.

In addition to the manufacturer's view, the way that people think about and interact with smart homes must be taken into account [9]. A research study conducted by Eggen and colleagues [10] reveals a clear discrepancy between people's home experience and available technology, which contributes greatly to a lag in the wide deployment of smart housing systems. Further studies have been conducted to understand what 'home' actually means to its dwellers. A variety of techniques (questionnaires, drawings, and videotaped sessions) were employed by the Media Interaction Group at Philips to encourage family members to express what home meant to them [11]. User views can be summarized as "Home is a feeling. It is co- 
zy, trusted, and safe place to return to; where you can be yourself and do what you want; where your own things are; where you meet the people you love and like". When asked how they would prefer to live in a technologically advanced or smart home, most users were primarily concerned with comfort and household tasks and had no preference for the domicile designation or type of technologies incorporated.

Bonino \& Corno [12] found similar results when examining user expectations of the smart home through a series of surveys exploring the role of Ambient Intelligence (AI) in shaping future home visions. Poll findings reveal that the gap between user expectations and existing solutions is actually narrower and easier to bridge than it may appear and the demand was primarily on making daily tasks more automated. Table 1 shows a sample of poll answers, illustrating the type of requests users made as well as involved technologies and timeframes.

To summarize, the common perception of smart homes is connectivity and remote control for more convenient, safe, and easy-to-use spaces at all times. What users expect (and manufacturers aim to deliver) from a smart home is increased comfort, reduced human intervention, and automated task completion. This fosters a passive role for occupants, as the ambient environment actively takes care of trivial chores such as turning off the lights when people go to bed. The typical perception of the smart home is therefore for an active design with a passive occupancy.

Blumendorf [7] points out that this perception of smart homes is often in conflict with sustainability goals, as it leads to an increased need for computational devices and the energy they consume. Intille [13] goes further, arguing that home automation reduces resilience, as it takes decision-making out of the hands of the home occupants, and hides the basis for its decisions. The building's users then don't understand what the automated systems are doing, and are unable to tell whether or not the building is working as it should. When the technology inevitably breaks down, they may not even notice; the building seems to continue to do the wrong things. The alternative, he argues, is that smart homes should inform, but not take action. For example, by indicating to homeowners when opening a particular window might help cool the home, a smart building could gently teach people how their buildings work, while giving them agency over when and how to act.

A more critical view is offered by Strengers [14], who argues that smart home researchers make naïve assumptions about the nature of the typical homeowner as "resource man", someone who understands his environmental impacts and would like to reduce them, but is too lazy, busy, or uninterested to manage that himself. In the process, such research often falls into the "colonial impulse" described by Dourish and Mainwaring [15]: the idea that a better world can be created by sharing the knowledge and technology from research labs in the rich and privileged parts of the world, without any regard for the lived experience and cultural diversity of the recipients of these benefits. The result is the tendency to create "one size fits all" solutions. To counter this, Strengers argues that we need to think more broadly about diversity in a number of ways: cultural and gender diversity of the people being designed for;
TABLE I. HOUSEHOLD-RELATED USER REQUIREMENTS AND SOLUTIONS EMERGING FROM THE POLL [12]

\begin{tabular}{|c|c|c|}
\hline $\begin{array}{l}\text { Requirement } \\
\text { (poll answer) }\end{array}$ & Possible solutions & Feasibility \\
\hline $\begin{array}{l}\text { Auto-Clean home when } \\
\text { I'm out: above all vacuum } \\
\text { cleaner }\end{array}$ & \multirow{2}{*}{$\begin{array}{l}\text { Home Automation, e.g. } \\
\text { KNX or MyHome, or Smart } \\
\text { Home technologies (for } \\
\text { scheduling and presence } \\
\text { detection) integrated with } \\
\text { cleaning robots (e.g. the } \\
\text { Roomba vacuum cleaner) }\end{array}$} & present \\
\hline Clean yourself, please & & $\begin{array}{l}\text { present / } \\
5 \text { years future }\end{array}$ \\
\hline $\begin{array}{l}\text { Give me an alert when } \\
\text { food in the cupboard is } \\
\text { near its "Expiration } \\
\text { Date" }\end{array}$ & $\begin{array}{l}\text { Object tracking (e.g. through } \\
\text { barcode or RFID) }\end{array}$ & $\begin{array}{l}\text { present } / \\
5 \text { years future }\end{array}$ \\
\hline $\begin{array}{l}\text { Tell me what do I have to } \\
\text { buy at the supermarket }\end{array}$ & $\begin{array}{l}\text { Intelligence, User profile, } \\
\text { Smart appliance \& home } \\
\text { automation }\end{array}$ & \\
\hline Please, iron the clothes & Smart appliance, Robotics & 5 years future \\
\hline $\begin{array}{l}\text { Cook milk and coffee for } \\
\text { breakfast } 2 \text { min after the } \\
\text { wakeup call }\end{array}$ & $\begin{array}{l}\text { Smart appliance, Schedul- } \\
\text { ing, Robotics? }\end{array}$ & $\begin{array}{l}\text { present / } \\
5 \text { years future }\end{array}$ \\
\hline $\begin{array}{l}\text { Wash iron and order } \\
\text { clothes in their correct } \\
\text { places, without forgetting } \\
\text { the moth repeller }\end{array}$ & $\begin{array}{l}\text { Smart appliances and Robot- } \\
\text { ics }\end{array}$ & $\begin{array}{l}15 \text { years } \\
\text { future }\end{array}$ \\
\hline $\begin{array}{l}\text { Prepare my lunches and } \\
\text { dinners according to my } \\
\text { daily preferences, please }\end{array}$ & $\begin{array}{l}\text { Smart appliance, User pro- } \\
\text { file, Robotics, Intelligence }\end{array}$ & $\begin{array}{l}15 \text { years } \\
\text { future }\end{array}$ \\
\hline
\end{tabular}

diversity in the home experience (e.g. not all parts of the home have to be kept at the same temperature), and diversity in the rhythms and pace of home life. As an example of the latter, Pierce and Paulos [16] point out that as people turn more to local micro-generation of energy, they become more aware of daily and seasonal rhythms and adjust naturally, for example by scheduling "windy-day bread making" and "sunny-day laundering".

These critiques suggest that the typical approach to smart homes is entirely backwards. Instead of active homes reliant on complex networks of high-tech devices, we need simpler, passive homes, designed to suit the local environment rather than to fight against it. And instead of passive occupants, with no agency over their dwellings, we need to design for active occupants, who have agency over their homes, and adjust how they use the home according to local conditions.

In the next section, we present examples that show such an approach is already captured in centuries-old traditional (vernacular) architectural practices. We argue that our vision for smart and sustainable architecture, based on vernacular practices, offers a new paradigm of passive design and active occupancy.

\section{VERNACULAR ARCHITECTURE}

One of the most promising developments to emerge in architectural discourse within the past three decades has been the changed perception of tradition and innovation, and the growing realization that they are not mutually exclusive. Traditions relate to indigenous construction paradigms, or, more specifically, vernacular architecture. Vernacular architecture is a re- 
gion- or society-specific response to shelter needs, exploiting resources and building materials available in the ambient environment such as mud, earth, straw, wood, and stone. Through trial and error, generations of community members, builders and craftsmen, often untrained professionally, developed local techniques derived from their needs and the properties of the available materials. Vernacular architecture can be traced back to pre-historic times and is considered a unique identifier of the civilization producing it.

In the seminal 1964 book, "Architecture without Architects", Bernard Rudofsky made the radical comment that "There is much to learn from architecture before it became an expert's art" [17]. More recently, vernacular architecture has been recognized as a resource with considerable potential for understanding and implementing the principles of sustainable design and construction [18]. That is because vernacular architecture was built on inherently sustainable principles such as resource limitations imposed by financial or natural factors, yet succeeded in offering rational solutions to harsh climates and human needs.

Sustainable building practices in vernacular architecture relied on (1) simple, renewable, and naturally insulating materials, (2) ambient resources such the sun, wind, topography, soil, flora, and fauna, as well as (3) passive strategies such as siting, thick walls, and pressure differences to create healthy comfortable internal spaces with minimal damage to the environment [19].

In the previous section, we used the terms active design and passive occupancy to describe the typical dwelling model for smart homes. Vernacular architecture on the other hand relied primarily on passive design strategies and active occupancy. We identify the meaning of these terms next before delving further into the smart, sustainable, and passive features of vernacular architecture.

\section{Passive vs Active Design AND OCCUPANCY}

Active systems refer to heat pumps, forced-air Heating, Ventilation and Air Conditioning (HVAC), artificial lighting, and responsive building components that perform tasks, predict and fulfill user needs, and optimize resource consumption. They require purchased or manufactured energy such as electricity or natural gas to operate and moderate indoor environments, and a complex network of sensors and processors for control.

Passive design, on the other hand, uses ambient sources such as solar energy, wind, daylight, inherent material properties, and natural ventilation to create comfortable indoor spaces. By analogy, incorporating architectural features such as high windows, ventilation holes, fountains, and courtyards also count as passive contributors to privacy, environmental regulation, and thermal comfort.

Passive heating and passive cooling are the energy systems of utmost importance from a sustainability perspective. In passive heating, thermal energy flows naturally by radiation, conduction, or natural convection without mechanical assistance, and is related to solar energy. Passive cooling refers to the use of heat sinks and a variety of climatic influences to create thermal comfort in warm and hot regions. It is defensive against solar gain and heat transference through the building envelope, and it requires the evacuation of heat from the building to natural heat sinks [20]. Passive cooling systems in hot regions are classified into four major strategies: ventilative cooling, radiative cooling, evaporative cooling and mass-effect cooling. All four strategies use natural renewable energy resources, making vernacular homes more sustainable in terms of energy consumption. The more a building relies on passive systems, the more sustainable it is.

But vernacular architectural styles did no rely solely on passive design to ensure comfort. People played an active occupancy role, shifting which rooms they used throughout the day to avoid the sun and follow the cool breeze (and vice versa in winter), growing plants for shade and transpiration, dampening outdoor surfaces to cool the air, re-using water for irrigation and cleaning, and layering thick textiles and carpet in the cool months, among other practices. This noticeably contrasts with passive occupancy where dwellers no longer need to bother with trivial tasks such as turning off the lights, lowering the volume, turning on faucets at lower flows to reduce water consumption, turning on air conditioning, drawing curtains, or locking the door. In design for passive occupancy, the ambient environment senses their needs and performs the required chores.

The contrast in passive and active design and the type of occupancy it instigates lie in the planning, design philosophy, available resources, and lifestyle priorities. Passive systems are unlikely to offer the same level of control and optimum comfort that active systems afford, especially for dwellers accustomed to living standards in richer, developed nations. Yet the difference in reliability and in embodied and operational energy is a huge advantage. A rational blend of passive and active design systems is therefore a favorable strategy to provide more sustainable homes, made smarter with judicious use of ICT.

\section{FEATURES OF VERNACULAR HOMES IN EXTREME Climates: SMART, SUSTAINABle, AND PASSIVE}

Vernacular architecture relies largely on passive design characteristics. To demonstrate the smart and sustainable aspects of vernacular architecture, we analyze a typical traditional house built in an extreme climate region (hot and humid), breaking down its unique design components: compact urban fabric, site planning, design concept, building mass, envelope and materials, and natural ventilation.

The strategies discussed are taken specifically from the Middle East where temperatures reach $60^{\circ}$ Celsius and $80-90 \%$ humidity levels in the summer. Other hot regions have their own analogous systems and adaptations, and many are useful for both temperate and cold climates too. The vernacular architecture in colder regions such as Europe and Canada have less pronounced strategies, with the hearth, draperies, and thick masonry walls being the major design strategies against winter chills. That is why we chose to focus on hot climate.

Sadly, most of the strategies discussed next have been abandoned (hence the use of past tense in the description of 

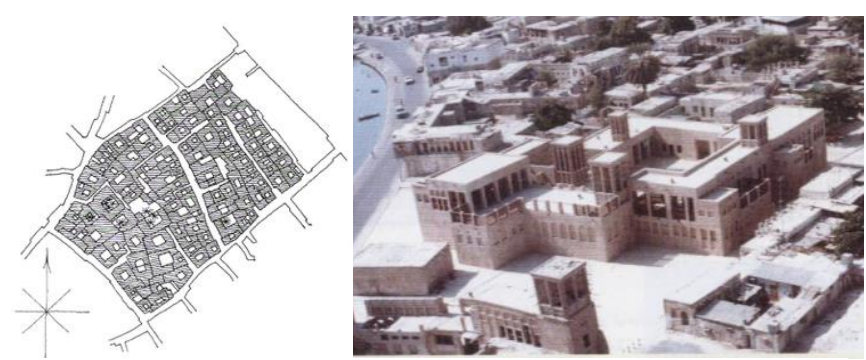

Fig. 1. Compact urban fabric in a traditional hot climate city

each), in favor of conventional detached structures and high rise concrete blocks moderated by active systems. It remains to note that the next section is rather loquacious but what makes these buildings smart lies in the details.

\section{A. Compact Urban Planning}

The extreme annual and diurnal variations and severe climate in most hot climate regions necessitated an approach to urban planning and housing forms that are well adapted to the ambient environment. City planning was the first step for sustainable design, to provide a compact urban fabric, shaded streets, narrow passageways, and uniquely shaped houses.

This approach was so compact that buildings were integrated into one complex structure, to the point that individual houses were indistinguishable. This ensured that fenestrations and alleys would remain shaded during the summer, and trap heat in the winter, to protect against extreme temperatures and sand storms, and to minimize the thermal load on building envelopes, as illustrated in Fig. 1.

In selecting a suitable building orientation for a hot climate, the objective was to minimize the interior daytime temperature and produce shaded exterior living spaces. Houses and their contiguous outdoor spaces were oriented to defend against wind-borne dust. To plan any site, the position of the sun was determined for all hours of the day during all seasons as well as the direction of the prevailing winds, especially during the hot season. In addition, reflection from adjacent buildings and wind shadowing contribute to specific microclimate for each building location and so were taken into account in the design [21].

The urban fabric in traditional cities was organic; thus most of the plots were irregular. To obtain the internal openings
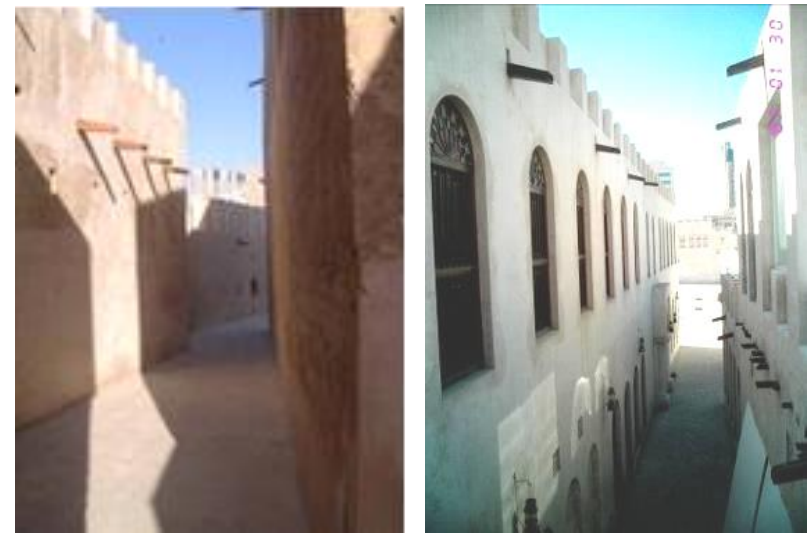

Fig. 2. Narrows alleys providing shade for pedestrians
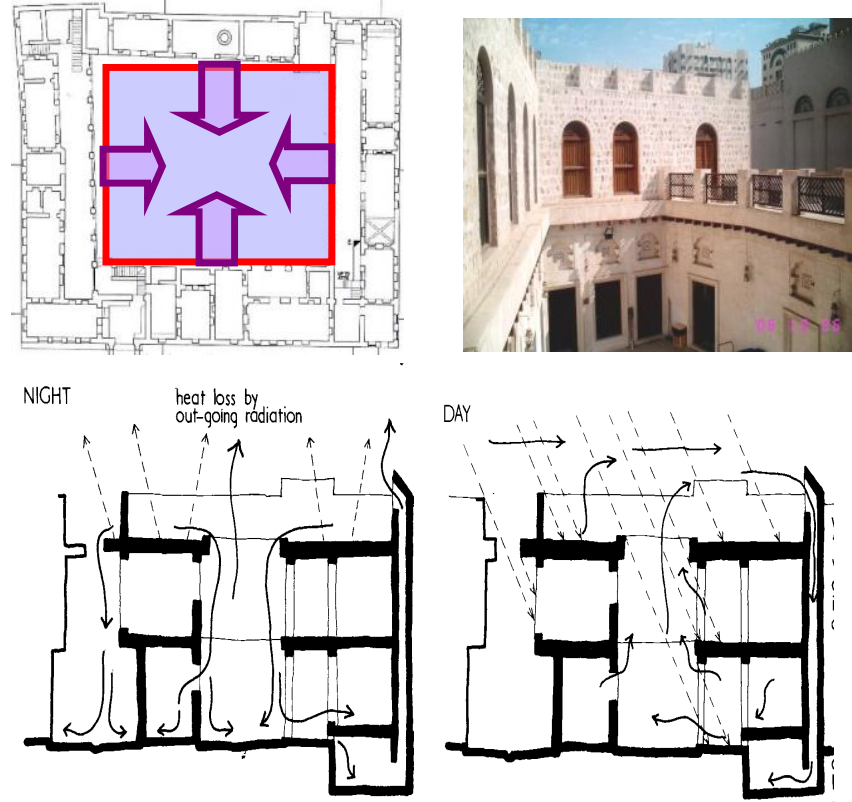

DAY

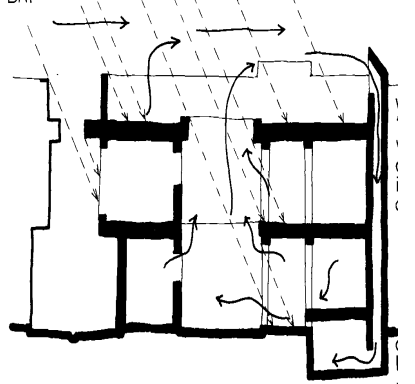

Fig. 3. Courtyards as essential design elements in vernacular houses and their thermal mechanisms [22]

integral to traditional houses, a regular geometric courtyard was the first to be planned. Then passageways and rooms were arranged around the courtyard. The irregular parts and undesirable angles were modified by changing the depth of the walls, which were then adapted as shafts, service areas, niches, cabinets, or fixed furniture.

\section{B. Site planning}

Wind movement and humidity were important factors and were considered simultaneously with the direct and indirect effects of the sun to establish the optimum orientation [21]. Residential districts and clusters were made up of a dense composition of dwellings. Houses often shared walls. Wall sharing promoted smaller surface to volume ratio, thus reducing the common problem of heat gain in buildings [23]. The primarily solid walls within the organic urban fabric permitted houses to be extremely close to each other, so that alleys and passageways were only a few feet wide, especially within residential sectors. This closeness made walls act as shading devices to reduce the effect of solar heat and create shaded alleys for pedestrians, as illustrated in Fig. 3.

The contrast between light places and shaded surfaces helped create pressure differences, causing air movement from high to low pressure zones, which enhanced the natural ventilation around and inside houses.

\section{Design Concept}

The design philosophy in vernacular homes was based on fulfilling privacy and protection requirements. This governed the layout, spatial relations, and architectural details. 


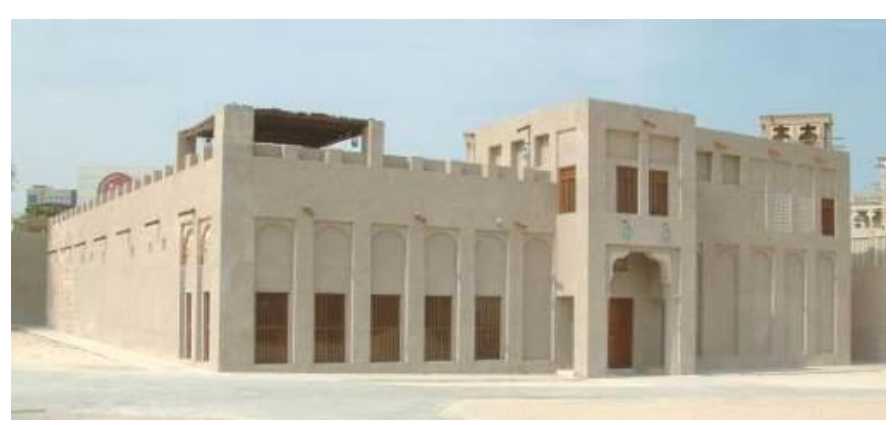

Fig. 4. Solid building mass and small shuttered openings minimize heat gain

A central interior courtyard onto which all rooms opened was restricted to family use, regardless of religion. Courtyards provided shading and privacy in an open space where most of the day activities were located [24].

Courtyard houses were flexible, accommodating physical expansion and the particular needs of extended families. Environmentally speaking, the courtyard was a thermal regulator, thus exposure to the sun was avoided by keeping the courtyard small and overshadowed by high walls, wide eaves, and foliage [25]. During the hot months, courtyards functioned in three phases. During the first (night) phase, the cool air descended into the courtyard and filled the surrounding rooms. Building surfaces and even furniture were cooled at night and remained cool until late afternoon. In addition, the courtyard lost heat rapidly by radiation to the clear night sky [20]. During the second (midday) phase, sun rays struck the courtyard floor directly. Some of the cool night air then flowed out of the surrounding rooms, inducing convection currents for further comfort. The courtyard then acts as a chimney when the outside temperatures are highest (See Fig. 3). During the third phase, the courtyard floor and the inside of the house warmed and further convection currents were set up by late afternoon. Most of the cool air trapped within the rooms had spilled out by sunset. During the late afternoon, the streets, courtyard, and buildings were further protected by shadows of adjacent structures. As the sun sets in the hot arid zones, the air temperature fell rapidly and the courtyard began to radiate rapidly to the clear night sky. Cool air began to descend into the courtyard, completing the cycle [20].

\section{Building Mass}

The building mass in hot region vernacular architecture was largely solid with very small exterior openings, to protect the interior spaces from the harsh climate. Besides climatic conditions, traditions and social values greatly affected size, numbers, and location of openings in building external treatments (see Fig. 4). A passive mechanism for reducing solar gain and heat loss was to minimize the envelope surface area [26]. While a sphere has the least surface area for a given volume, a rectilinear building that is square in plan is more practical to build than a sphere and provides a better ratio of useable floor area to envelope surface area. Complex shapes can double or even triple the envelope surface area compared to a building of similar size and form with flat surfaces [27]. Therefore, the masses of traditional houses in hot climates were simple and flat, to minimize surface area.

\section{E. Building Envelope and Materials}

The building envelope was the main element that protected occupants from the worst extremes of the external climate, through passive energy attained from natural and renewal resources. It provided a filter, modifying the climate sufficiently for the internal conditions to be more acceptable [28]. The envelope reflected as much sun rays as possible, resisted heat transfer, and minimized heat and solar gain for cooler interior conditions [29]. The envelope's ability to deal with hot harsh climate helped minimize the internal temperature fluctuation, delaying the effect of maximum afternoon temperature for several hours as it travelled through the thick wall, until night, when the outside temperatures dropped and open spaces (such as the roof) could be used for living and sleeping. This is an example of active occupancy because dwellers changed rooms based on the climate and time of the day. In addition to envelope properties, dwellers used textiles, draperies, and carpets to enhance thermal comfort and interchanged them across seasons.

The thermal properties of envelope materials such as heat capacity, thermal conductivity and resistivity, reflectivity, and emissivity determine heat transference and solar radiation reflection. Thus, the choice of building materials was of great importance. Envelopes were built from indigenous building materials such as limestone and adobe appropriate in physical properties to climatic conditions and the construction techniques employed by the society that produced the architecture.

Traditional building materials such as brick, mud, sand, stone, palm trunks, and wood are available naturally, and were generally low in embodied energy and toxicity [30]. They are also recyclable, reusable, energy efficient and environmentally sustainable. They are good thermal insulators too when used as thick walls with minimum external openings. These traditional building materials tended to be available locally, and are better suited to climatic conditions; thus, they created comfortable internal environment passively and naturally.

\section{F. Natural Ventilation}

Natural ventilation was one of the passive cooling strategies that vernacular architecture employed to create comfortable indoor climate, through evaporative cooling. Vernacular houses were oriented with respect to prevailing wind and lank facades were oriented to shield from the hot wind.

Wind towers were the main natural ventilation feature, complemented by courtyard and air pullers. In cooler seasons when air drafts were undesirable, dampers were easily shut and wind catcher openings covered (see Fig. 5). A typical wind tower resembled a chimney, with one end at the ground floor and the other end rising from the roof. The upper part of the tower was divided into several vertical air passageways that sprout into openings on the tower sides. There were variations in the tower's top side, cross section of air passages, placement and number of the openings, as well as tower location with respect to structure it cools. The lower parts opened on the ground floor into the central hall or main family room. The 


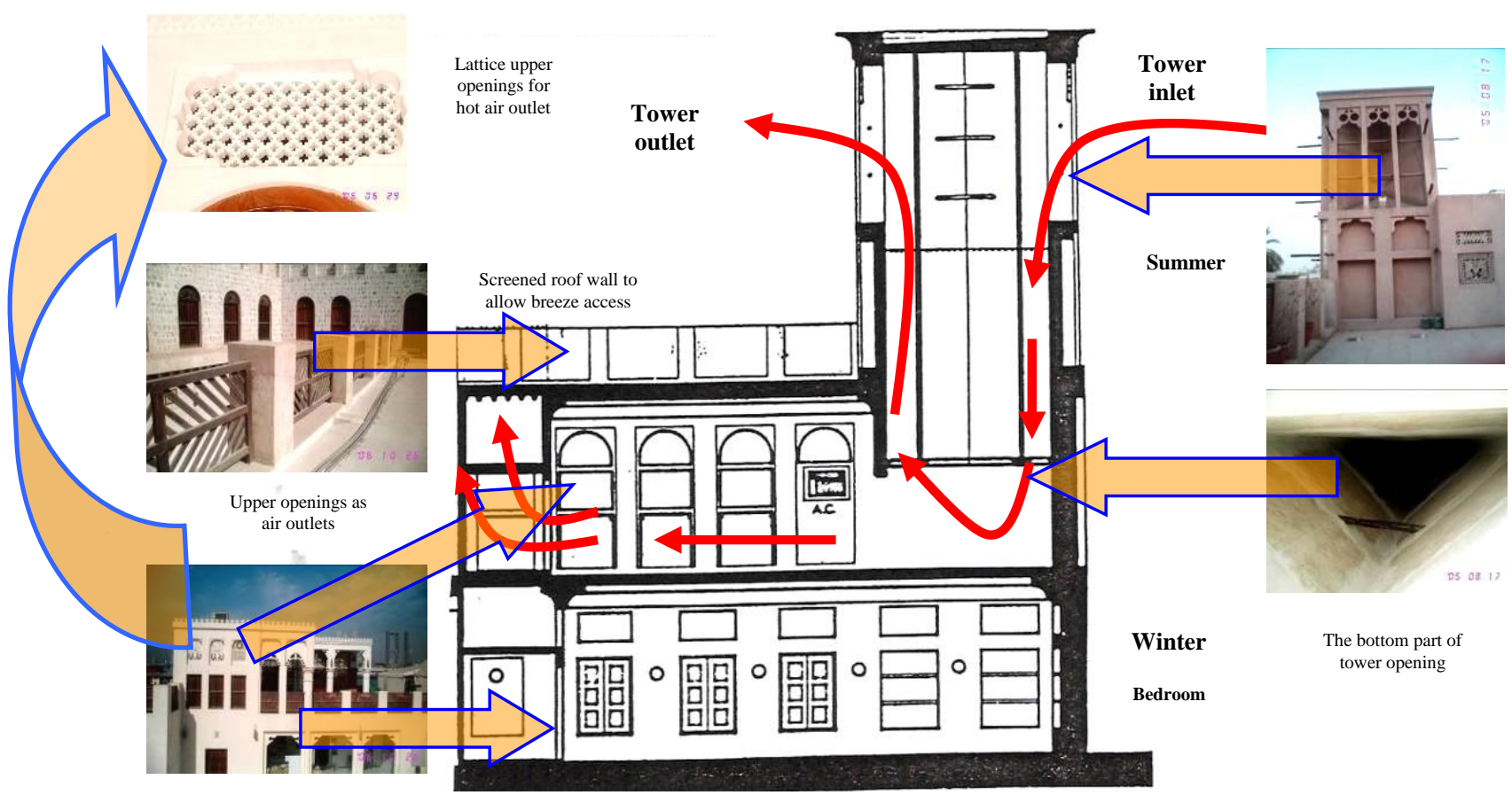

Fig. 5. Natural ventilation through upper spaces in a vernacular home

flow of air through different parts of the building could be controlled by opening or closing the grilles upward and downward [21].

Wind towers were placed about fifteen meters above the ground. At such height, wind velocity is about one and half times greater than at one meter above ground level. When the breeze entered the tower through an opening, it collided with the wall within it and was forced to travel downwards through a relatively long neck. At least half the length of the tower was an enclosed funnel that increased the breeze velocity, and made it lose some of its heat. The breeze accordingly reached the inside of the rooms at comfortable speed and with a lesser temperature than outside [31]. To maximize ventilation in regions with changing winds, wind towers were multi-directional (had four vertical openings in four directions), catching the breeze from whichever direction it might come from. Wall fenestrations provided further cross ventilation.

Air pullers were additional ventilation features. They also forced the breeze inside through high openings located on external wall recesses. If privacy was a concern, openings were replaced with two thin parallel walls with a distance of about 10 centimeters in between. This design enabled the wind to strike the upper wall, be deflected into the opening and then pass though the lower wall into the adjacent room, providing both air and privacy [32].

Finally, courtyard performance as a thermal regulator played an essential role in facilitating natural ventilation within the house throughout the day. This was achieved using temperature fluctuation, difference in pressure zones, and land and sea breeze direction change between day and night.

\section{RETHINKING THE CONCEPT OF SMART HOMES}

Vernacular architecture was based on available resources, human needs, and climatic conditions. It exemplified the principles of sustainable design through solutions that evolved over long periods of trial and error using local materials and technology emerging from the ambient natural and cultural environment. While the level of detail in the previous section might be of more interest to architects than to ICT practitioners, it is the deliberate design strategy and attention to intricacies in site planning, orientation, building form, fenestrations, etc. that showcase the brilliance of vernacular architecture in delivering shelter and comfort while being inherently sustainable.

Recall the smart and sustainable home model we presented earlier; it has active design (systems and building components perform tasks, predict and fulfill user needs, and optimize resource consumption) and passive occupancy (dwellers no longer need to bother with tasks as trivial as turning off lights or drawing curtains). Then we presented a typical vernacular home from a hot region with its passive design features (cooling, ventilation, privacy, etc.) and active occupancy (shifting activities throughout the day, growing plants, dampening the air, using textiles, etc.).

Consider any of the homes pictured in section IV, compared to a hypothetical modern house or high rise apartment tower located in a hot climate region (Dubai/UAE or Phoenix/USA for example). The latter have floor to ceiling windows facing south and west. The house/apartment is equipped with a smart thermostat controlled by an algorithm on the manufacturer's server as well as from a smart phone. It blasts the air conditioning on at maximum fan speed when the occupants' 


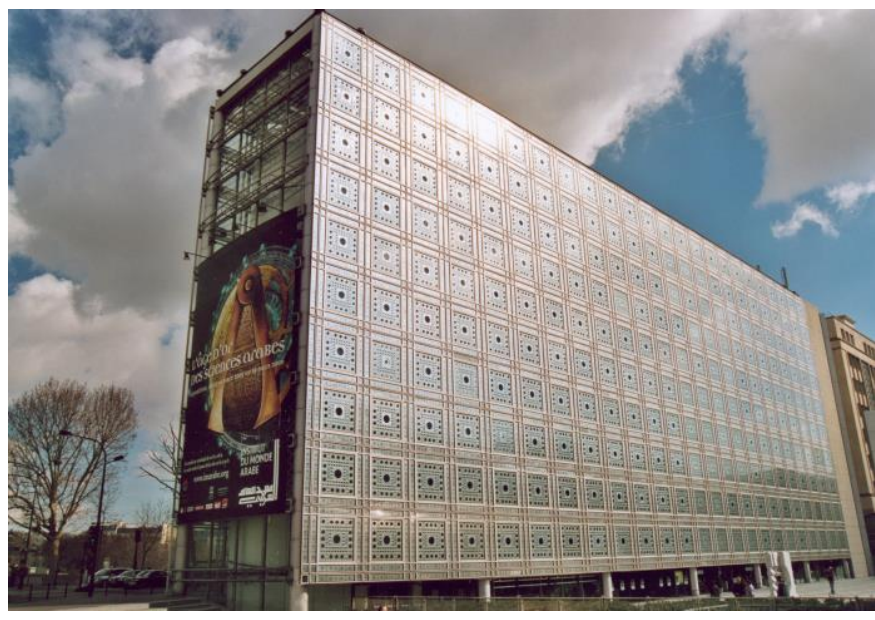

Fig. 6. Institut du Monde Arabe in Paris Mechanical Façade [33]

car GPS coordinates and traffic conditions indicate that they are half an hour away. At this time, the temperature inside is over $34^{\circ}$ Celsius, despite the double pane glass, because the motor responsible for drawing the curtains after occupants leave in the morning to deflect solar rays stalled due to a compatibility error with the main control firmware. The occupants are not aware of the failure because the curtain manufacturer went out of business and ceased sending status updates by email.

It is clear which home is more sustainable from an environmental perspective. We also argue the former is the smarter building too. A house that operates through hundreds of sensors and actuators controlled by cloud servers located in remote data centers depends too much on technology that is prone to failure. The moment failure occurs (due to bugs, viruses, software incompatibilities, and energy outages), such a home is no longer smart or sustainable. By then, the occupants themselves may no longer be smart enough to operate it because they simply forgot how to actively rationalize resources (remembering to turn off the lights for example); technology took care of it all.

This isn't just a hypothetical story. Jean Nouvel's highlycelebrated Institut du Monde Arabe in Paris has 240 photosensitive shutters on its façade; opening and closing with a mo- tor to control the amount of solar light and heat entering the building system (see Fig. 6). They are futuristic and beautiful, but the hardware no longer works due to dust and the amount of required maintenance. Software in smart homes is prone to the same fate. Overtime, the reliability of the smart systems can decrease not only due to hardware failures but because the software itself ages, and even with maintenance and bug fixes, errors are introduced to the point where the only solution is to abandon the product or cease development [34].

So how reliable is technology? And how abundant and lasting are the required energy sources? In the above scenario, which home will remain cooler (or warmer) should a power outage or cyber-attack occur? Which home will be less impacted by fluctuations in oil production?

A vernacular home is smart, not because of embedded computing technology, but due to its orchestration, material properties, layout, orientation, construction rationale, tectonics, assemblies, and occupancy patterns. It turns hot air into cool breeze, blinding sun rays into soft shadows, walls into thermal tanks, and dwellers into activity regulators. It may not be as convenient as a conventional modern smart home, but it is guaranteed to provide comfortable interior spaces for longer and more reliably. Is that not smart and sustainable?

We now propose a fruitful amalgamation between active and passive design, made possible through ICT systems, to orchestrate feasible and sustainable homes desirable by current and future generations.

\section{INCORPORATING VERNACULAR PRINCIPLES INTO SMART \& SUSTAINABLE HOMES}

We have developed a design for a sustainable home in an extreme (hot) climate region based on a checklist of vernacular motifs created by one of the authors. The design remarkably resembles recent villa developments in Dubai/UAE but the difference in performance is substantial - Figs. 7 and 10.

We tested the digital design model to simulate its environmental performance, using the environmental assessment software, $D K$-Solar, to calculate energy consumption for the given design while varying building orientation, window treatment (internal and external shading devices), glazing types, wall materials, fenestration configurations, and other parameters.
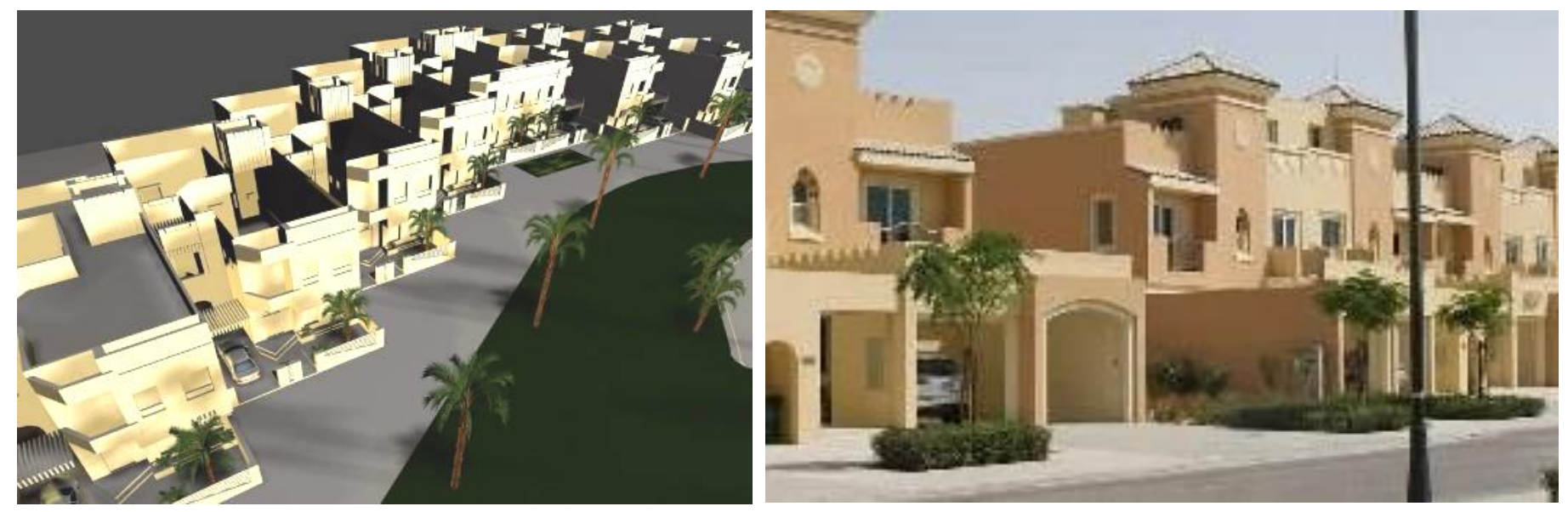

Fig. 7. Design model (left) Contemporary residential district in Dubai [35] 

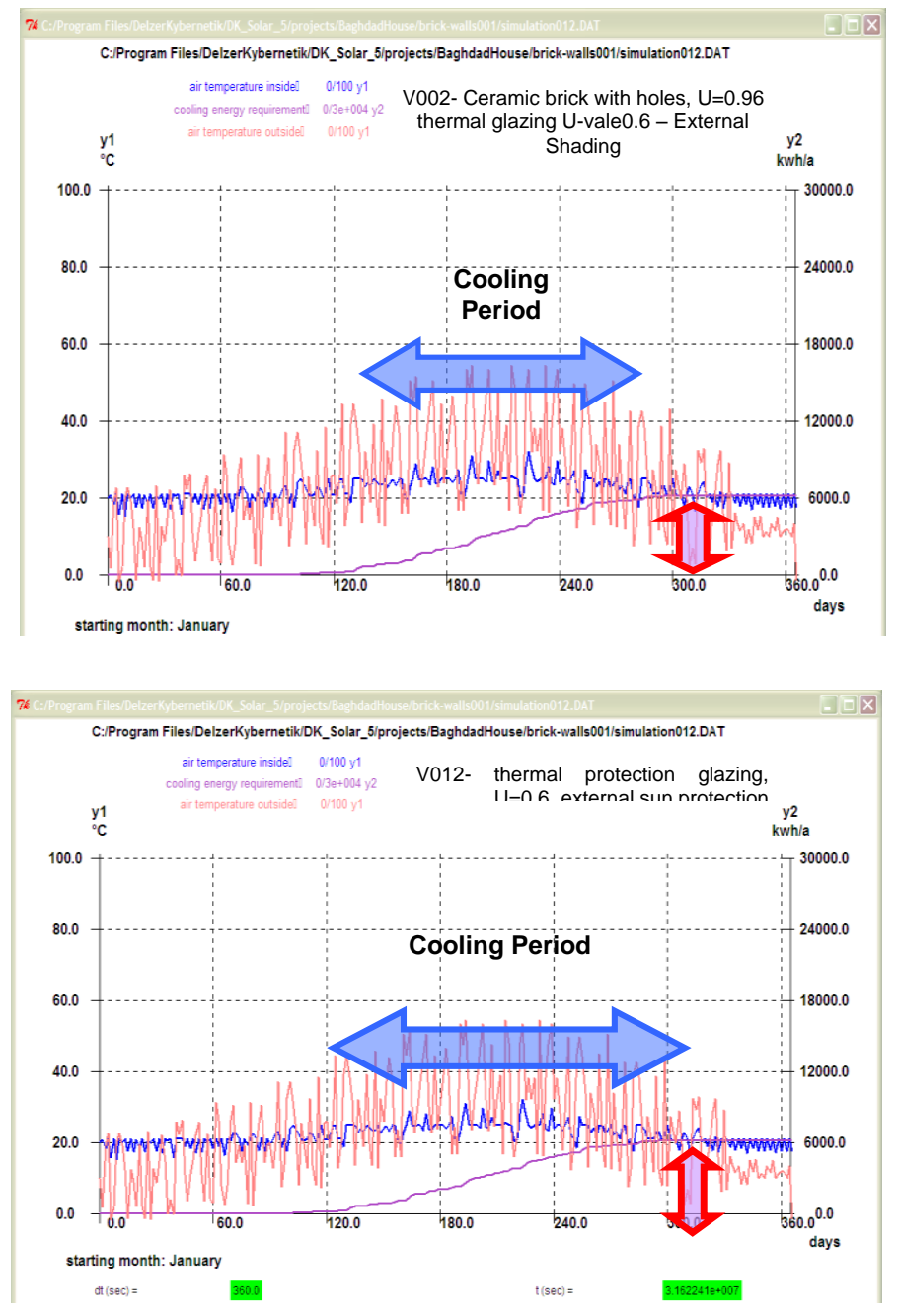

Fig. 8. Cooling loads in north-south orientation for V2 and V12

Twelve combinations were tested with one or more variables modified each time. For instance, V1 assessed performance with a $24 \mathrm{~cm}$ brick wall, no thermal insulation, single glazing, and no shading devices; V2 with a $24 \mathrm{~cm}$ brick wall, no thermal insulation, single glazing, and internal shading devices; V12 with $24 \mathrm{~cm}$ brick wall, thermal insulation, single glazing, and external shading devices and so on. For this analysis, combinations were selected manually, although we envisage this could be automated for efficiency, with a load optimization algorithm to produce and test combinations.

Since the design was for a house in a hot region, the goal was to minimize cooling energy consumption during the hottest months (May to September). In extreme hot climates, mechanical cooling cannot be avoided if contemporary comfort levels are to be maintained. However, the cooling load can be reduced drastically when incorporating passive design strategies.

The simulations determined the best building orientation to be North-South, which, with thermal insulation, reduced energy use by around $45 \%$. The results were even better when using double-glazing, porous brick, and internal and external shading devices (See Fig. 8). This energy savings percentage is a lower bound, because the assessment software does not take
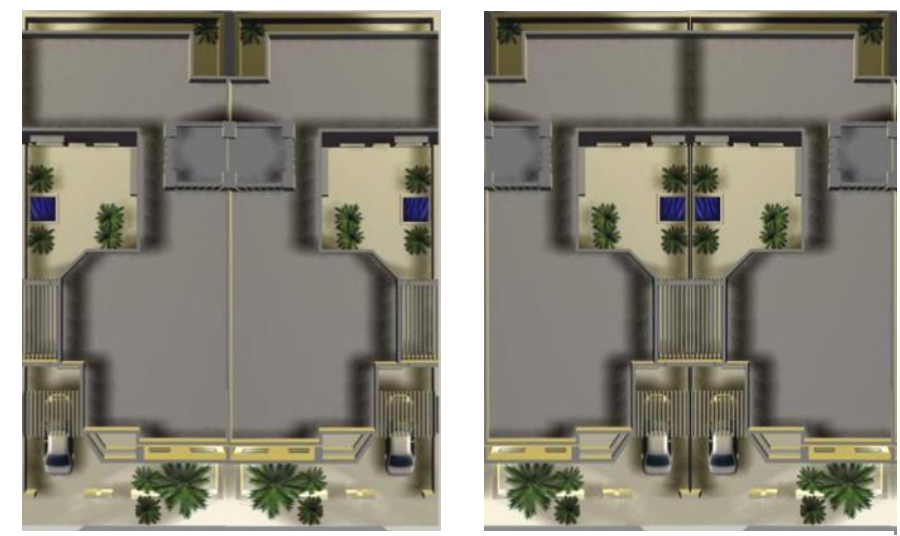

Fig. 9. Alternative configurations for adjacent homes: A (left) and B (right)

into account the cooling introduced by passive ventilation and wind towers. So it is expected that there will be many days in the hottest months when mechanical cooling is not even needed, thus reducing the anticipated cooling load.

Note that the design and results shown in this section were implemented on the scale of a single house and do not consider aggregations or neighborhood layouts. For example, adjacent homes in configurations A and B (Fig. 9) are bound to operate differently because they disperse and absorb the sun and wind differently. Furthermore, larger home aggregations have greater impact on creating a microclimate that can improve or jeopardize building performance, shading patterns, surface water runoff, storm protections, etc.

The main design concept was based on fulfilling the three dimensions of sustainability: environmental, social, and economic. The design aimed to minimize the building environmental footprint by adapting passive design strategies using available building materials, local construction techniques and labors, and natural environmental solutions. The checklist was inspired by vernacular architecture principles taking in account modern life style, social values, and occupants' daily routine:

- Compact Planning: minimize exposure to direct sun light; keep side exterior walls solid to provide flexibility when grouping houses for compact planning.

Introvert Design: make an inner courtyard the focal point for the family's main outdoor activities, rather than a front porch or back yard. Most of the living spaces should overlook this courtyard.

- $\quad$ Social Values: consider privacy and family relations through space locations and orienting family spaces towards the inner courtyard.

- Natural Ventilation: provide natural ventilation throughout the house, inspired by passive solution used in vernacular architecture to create comfortable indoor environment in moderate seasons and minimize cooling load and energy consumption in hot seasons.

- $\quad$ Passive Design and Natural Resources: use natural resources such as the sun and wind to create comfortable indoor environments, through evaporative cooling and natural ventilation. 

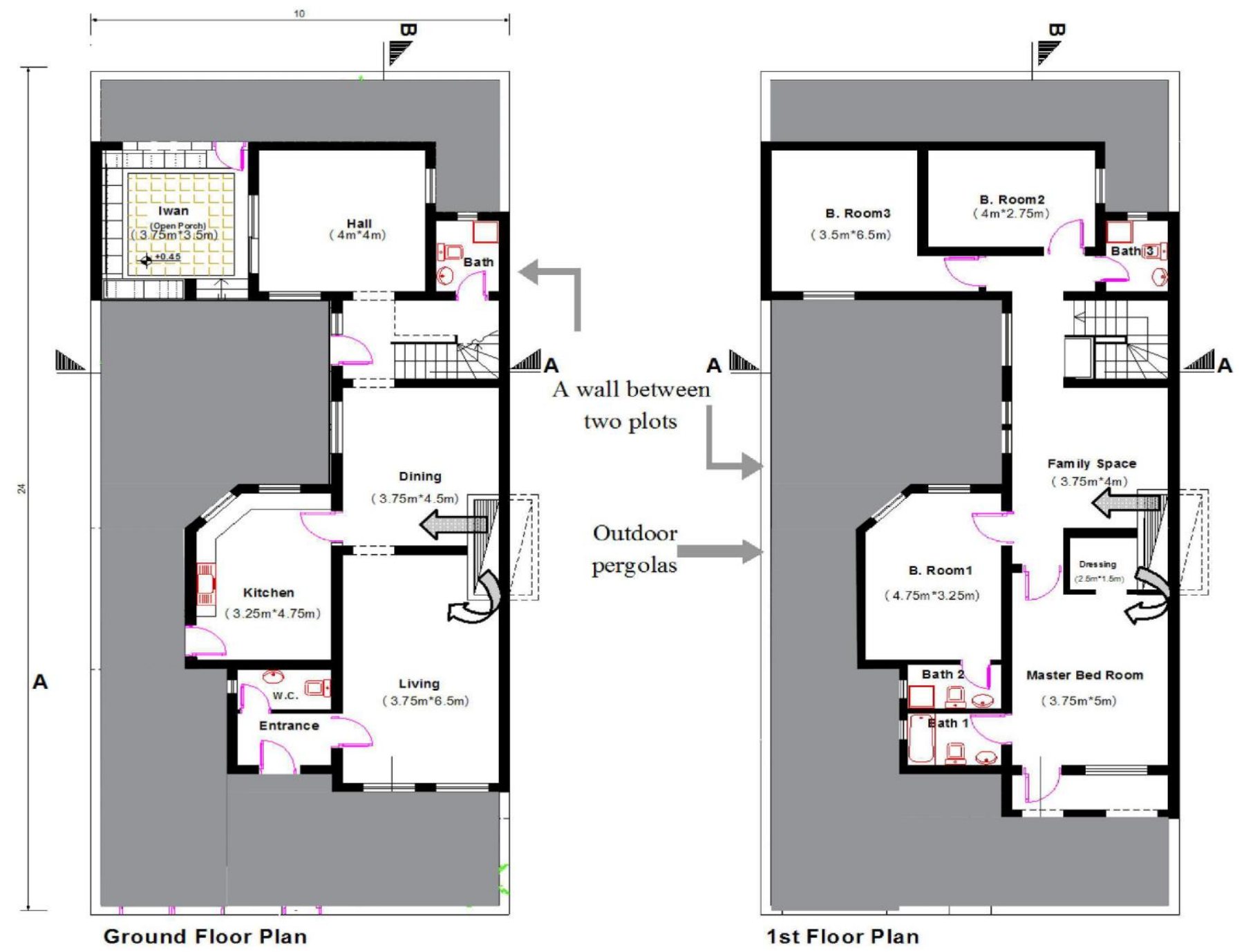

Fig. 10. The proposed sustainable house floor plans where the indoor and outdoor spaces (shaded areas) are integrated

In the cold season, the courtyard floor and building envelope act as thermal storage during the day and emit the heat back to inner spaces during the night. In moderate and hot seasons, the integrated system of courtyard and stairwell work as wind tower, using temperature fluctuation between the day and night to create a flow of natural ventilation. In cold seasons or undesired wind situations, the staircase/wind tower flexible openings can be closed or re-oriented. Open and closed spaces are integrated with shaded and sunny surface to create different pressure zones to enhance air movement. Other conventional sustainability features such as energy-saving water fixtures and plumbing, grey water recycling, rainwater collection, and LEED inspired criteria are incorporated.

\section{CONCLUSIONS}

Resource limitations and reliability concerns are big challenges for smart homes. These lead us to question the assumption that high-tech active control systems for passive users offer a sound basis for the sustainable home of the future.
Too often, this approach to the design of smart homes end up with a very narrow conception of the needs of the user, and a 'colonial' attitude to the delivery of high-tech solutions irrespective of the local context.

In contract, the vernacular architecture, which our ancestors orchestrated with simple yet brilliant solutions and techniques to combat harsh climates, was much smarter.

We have argued for an approach that uses vernacular design principles in domestic buildings, reversing the usual assumption of active buildings and passive occupants. This approach represents a radical shift in the way that ICT systems are used to create the smart home. We argue that the role of ICT should be in the use of software tools to supplement human expertise, to improve design performance, and to educate dwellers on active occupancy. It results in homes and communities that are smart by virtue of design, rather than because of embedded technology.

Beyond the examples we have presented, we also need to go beyond the individual house. We need systems to investigate the forces acting at the neighbourhood level, which affect 
cooling/warming/depressurizing/etc. of the air before it even reaches each house. This is the type of future work we suggest for smart and sustainable homes: to encourage a comprehensive approach to design where the domestic built environment is seen as an integrated system of units (houses) including streets, vegetation, pavement, shaded areas, walkways and alleys. This was clearly evident in traditional cities in hot regions; organic fabric played an important role in modifying harsh climatic conditions before affecting the building envelope. There is great untapped potential in this area for the ICT community to unleash.

\section{REFERENCES}

[1] Tomlinson, B., Blevis, E., Nardi, B., Patterson, D. J., Silberman, M. S., \& Pan, Y. (2013). Collapse Informatics and Practice: Theory, Method, and Design. ACM Transactions on ComputerHuman Interaction, 20(4), 1-26.

[2] Blevis, E., \& Blevis, S. (2010). Hope for the best and prepare for the worst. Interactions, 17(5), 26.

[3] Horning, J., \& Neumann, P. G. (2008). Risks of neglecting infrastructure. Communications of the ACM, 51(6), 112.

[4] Nathan, L. P. (2008). Ecovillages, values, and interactive technology. In Proceeding of the twenty-sixth annual CHI conference on Human factors in computing systems (CHI'08) (pp. 3723-328). New York, New York, USA: ACM Press.

[5] Nelson, T. H. (1997). Crush and crash: logic of a terrible tomorrow. Communications of the ACM, 40(2), 90-91.

[6] Saad al-sumaiti, A., Ahmed, M. H., \& Salama, M. M. A. (2014). Smart Home Activities: A Literature Review. Electric Power Components and Systems, 42(3-4), 294-305.

[7] Blumendorf, M. (2013). Building sustainable smart homes. In Proceedings of the First International Conference on Information and Communication Technologies for Sustainability (ICT4S'2013), pp. 151-158.

[8] Smart Home USA http://www.smarthomeusa.com/

[9] Mennicken, S., Vermeulen, J., \& Huang, E. M. (2014). From Today's Augmented Houses to Tomorrow's Smart Homes : New Directions for Home Automation Research. UbiComp'14 Proceedings of the 2014 ACM International Joint Conference on Pervasive and Ubiquitous Computing, (September), 105-115.

[10] Eggen, B., Hollemans, G., \& van de Sluis, R. (2003). Exploring and enhancing the home experience. Cognition, Technology \& Work, 5(1), 44-54. doi:10.1007/s10111-002-0114-7

[11] Philips. (2002). Philips Research Home. Retrieved from http://www.research.philips.com

[12] Bonino, D., \& Corno, F. (2011). What would you ask to your home if it were intelligent? Exploring user expectations about next-generation homes. Journal of Ambient Intelligence and Smart Environments, 3(2), 111-126.

[13] Intille, S. S. (2002). Designing a home of the future. IEEE Pervasive Computing, 1(2), 76-82.

[14] Strengers, Y. (2014). Smart Energy in Everyday Life: Are You Designing for Resource Man? Interactions, 21(4), 24-31.

[15] Dourish, P., \& Mainwaring, S. D. (2012). Ubicomp's Colonial Impulse. In 14th International Conference on Ubiquitous Computing (Ubicomp 2012) (pp. 133-142). ACM Press
[16] Pierce, J., \& Paulos, E. (2012). The local energy indicator. Proceedings of the Designing Interactive Systems Conference on - DIS'12, 631

[17] Rudofsky, B. (1964) Architecture without Architects, an Introduction to Non-pedigreed Architecture. New York: Doubleday, Garden City, N.Y.

[18] Edwards, B. (2010) Rough Guide to Sustainability: A Design Primer. London: RIBA Publishing, 2010.

[19] Stang, A. and Hawthorne, C. (2005) The Green House: New Directions in Sustainable Architecture. Princeton Architectural Press, New York, 2005, p.13.

[20] Moore, F. (1993) Environmental Control Systems, International Edition, McGraw-Hill, New York, NY, USA, p.210.

[21] Hinrichs, C. L. (1987) The Architecture of the Courtyard House as Generated by Passive Solar Energy \& Other Factors, MPhil Thesis, Faculty of Arts, School of Architecture, University of Manchester, UK, pp. 138, 139, 176, 178.

[22] Ragette, F. (2003) Traditional Domestic Architecture of the Arab World, Axel Menges, Stuttgart, Germany, 2003

[23] Khawaja, M. A. (2002) DAR AS-SAKINA: Reinterpreting the Traditional Emirate House in the Design of a Modern Apartment Building in Sharjah, Final Project Research \& Design, American University of Sharjah, UAE, pp. 2, 12.

[24] Bagnid, A. (1989) Indigenous Residential Courtyards: Typology, Morphology \& Bio-Climate, International Association for the Study of Traditional Environments (IASTE) Working Paper Series, Vol. 6, pp. 40-56.

[25] Macintosh, D. (1973) The Modern Courtyard House: A History. London: Lund Humphries for the Architectural Association.

[26] Masonry Council of Canada, (1982) Guide to Energy Efficiency in Masonry \& Concrete Buildings, Masonry Council of Canada, Canada.

[27] Fethi, H. (1988) Natural Energy And Vernacular Architecture, 2nd Edition, United Nations University, Tokyo, Japan, p.45.

[28] Collier, T. (1995) Design Technology \& the Development Process in the Built Environment, 1st Edition, E\&FN Spon, UK.

[29] Giovani, B. (1998) Climate Considerations in Buildings \& Urban Design, JohnWiley \& Sons, Inc., USA.

[30] Kim, J.-J. and Rigdon, B. (1998) Qualities, Use, and Examples of Sustainable Building Materials, National Pollution Prevention Center for Higher Education, Michigan, USA.

[31] Al-Rostomani, A. H., (1991) Dubai and Its Architectural Heritage, Al-Safeer Publishing, Dubai, UAE, p. 166.

[32] Karim, L. (1999) Modernity and Tradition in Dubai Architecture, Al-Shindagah.

[33] Arab Institute Paris (2016) Open Architecture. http://www.openarch.com/

[34] Parnas, D. L. (1994). Software Aging. In Proceedings of 16th International Conference on Software Engineering (pp. 279287). IEEE CS Press.

[35] Better Homes (2011) Famous Residential Communities in Dubai. http://www.bhomes.com/blog/post/famous-residentialcommunities-dubai.aspx 